\title{
ATRIOVENTRICULAR DISCORDANCE: RESULTS OF REPAIR IN 127 PATIENTS
}

Thomas Yeh, Jr, MD, PhD

Michael S. Connelly, MD

John G. Coles, MD

Gary D. Webb, MD

Peter R. McLaughlin, $\mathrm{MD}^{\mathrm{c}}$

Robert M. Freedom, $\mathrm{MD}^{\mathrm{b}}$

Patricia B. Cerrito, $\mathrm{PhD}^{\mathrm{e}}$

William G. Williams, MD
Objective: The conventional management of patients with atrioventricular discordance is directed at associated lesions, taking advantage of physiologic "correction"; however, the morphologic right ventricle and tricuspid valve support the systemic circulation. Questions surrounding survival using this approach led us to analyze our institutional results. Methods: All patients with atrioventricular discordance undergoing biventricular repair were analyzed $(n=127,1959-1997)$, excluding those with functionally univentricular hearts. The ventriculoarterial connection associated with atrioventricular discordance varied and was most commonly discordant $(87 \%)$, but occasionally concordant $(6 \%)$, doubleoutlet right ventricle $(6 \%)$, or double-outlet left ventricle $(1 \%)$. At initial presentation, the most common lesions associated with atrioventricular discordance were ventricular septal defect $(86 \%)$, pulmonary stenosis $(64 \%)$, tricuspid regurgitation $(28 \%)$, and atrioventricular block (12\%). Nine patients underwent a double switch procedure to create ventriculoarterial concordance and the remainder were managed conventionally without correcting discordant connections. Results: Operative mortality was $6 \%$ and did not vary by associated lesion. Twenty years after repair, survival was $48 \%$. Within 20 years, $56 \%$ of patients required reoperation, usually for atrioventricular valve incompetence $(n=16)$, pulmonary stenosis $(n=16)$, or both $(n=3)$. Pacemakers were required in 50 patients, 4 before repair, 40 within 2 months of repair, and 6 remotely after repair. In early follow-up, the double switch procedure $(n=9)$ had equivalent mortality and a high pacemaker requirement for atrioventricular block. Conclusions: Analysis of conventional management of atrioventricular discordance revealed cumulative increases in mortality, systemic atrioventricular valve (tricuspid) replacement, complete atrioventricular block, and incidence of reoperation. Alternative management should be examined. (J Thorac Cardiovasc Surg 1999;117:1190-203)
$\mathrm{M}$ ost individuals born with atrioventricular (AV) discordance have associated ventriculoarterial (VA) discordance as well as major associated lesions includ-

From the Division of Cardiovascular Surgery, ${ }^{\mathrm{a}}$ Division of Cardiology, ${ }^{\mathrm{b}}$ Hospital for Sick Children, Toronto Congenital Cardiac Centre for Adults, ${ }^{\mathrm{c}}$ University of Toronto, Toronto, Ontario, Canada, and Division of Cardiothoracic Surgery, Kosair Children's Hospital, ${ }^{\mathrm{d}}$ Department of Mathematics, ${ }^{\mathrm{e}}$ University of Louisville, Jewish Hospital Heart \& Lung Institute, Louisville, Ky.

Received for publication June 23, 1998; revisions requested Dec 10, 1998; revisions received Feb 16, 1999; accepted for publication Feb 26, 1999.

Address for reprints: Thomas Yeh, Jr, MD, PhD, University of Louisville, Jewish Hospital Heart \& Lung Institute, 201 Abraham Flexner Way, Suite 1200, Louisville, KY 40202.

Copyright (C) 1999 by Mosby, Inc.

$0022-5223 / 99 \$ 8.00+0 \quad \mathbf{1 2 / 1 / 9 8 2 2 0}$ ing ventricular septal defect (VSD), pulmonary stenosis (PS), tricuspid insufficiency (TI), and AV block. Only 1 patient in this series had AV discordance without VA discordance. Conventional management of AV discordance has been directed at the presence of associated lesions, without addressing discordant AV and VA connections. Such an approach is under scrutiny because of late mortality and morbidity from failure of the tricuspid valve and right ventricle in the systemic position, and failure of the conduction system. The natural history of uncorrected AV discordance led to the conception ${ }^{1}$ and performance ${ }^{2}$ of the double switch procedure in which AV and VA connections are "corrected," allowing the left ventricle and mitral valve to support the systemic circulation. A 40-year experience treating 127 patients with AV discordance by biventricular repair 
was reviewed for insight into the management of this lesion.

\section{Methods}

All patients with AV discordance undergoing biventricular repair at the Hospital for Sick Children and the Toronto Congenital Cardiac Centre for Adults at the University of Toronto were analyzed by means of a chart review coupled with telephone survey of patients, their families, and physicians. Patients unsuitable for biventricular repair were excluded. The cohort included 127 patients and spanned almost 40 years from 1959 to 1997. Complete follow-up was available on $94 \%$ of the cohort through 1996 with a mean follow-up of $8.1 \pm 7.0$ years. Partial follow-up was available on $6 \%$ of the cohort and ranged from 0 to 18.5 years (mean $8.0 \pm 7.9$ years).

Anatomic variations. Situs solitus was present in $93 \%$ of the cohort and situs inversus in 7\%. The heart was levo-positioned in $82 \%$ of the cohort, dextro-positioned in $13 \%$, and meso-positioned in 5\%. The most common VA connection was discordant in $87 \%$ of patients. Double-outlet right ventricle $(6 \%)$ and VA concordance (6\%) comprised equal but smaller percentages of the cohort. A single case of doubleoutlet left ventricle was present.

The incidence of the 3 most common lesions associated with $\mathrm{AV}$ discordance managed with biventricular repair varied (Fig 1). VSD was present in $86 \%$ of the cohort, PS in $64 \%$, and TI in $28 \%$; however, patients had varying combinations of associated lesions. The most common of these was VSD combined with PS, accounting for 72 patients (56\% of the cohort). Four other combinations accounted for smaller proportions of the cohort, namely VSD/TI (14 patients, $11 \%)$, isolated VSD (17 patients, 14\%), isolated TI (13 patients, $10 \%$ ), and the combination of VSD/PS/TI (7 patients, 6\%). Notably, isolated PS (2 patients, 2\%) and PS/TI (1 patient, $1 \%$ ) formed extremely small percentages of the cohort.

Surgical repairs. The technique of repair varied according to lesion. In groups managed with conventional surgical repair, VSDs were closed by means of standard patch closure, attempting to avoid the conduction system as described by de Leval and associates. ${ }^{1}$ In the 95 patients undergoing VSD closure with a conventional repair, the approach to the VSD varied. Thirty-nine VSDs were closed through the left ventricle, 5 through the right ventricle, 43 through the right atrium, 3 through the left atrium, and 5 through the aorta. At the time of initial open repair, 27 patients with incompetent tricuspid valves were managed initially either by replacement (with a mechanical valve [19 patients, $70 \%$ ] or a bioprosthetic valve [3 patients, $11 \%$ ]) or by repair (5 patients, $19 \%)$. The management of 71 patients with PS used conduits (63 patients, 89\%), pulmonary valve and subvalvular resection (7 patients, 10\%), or REV (réparation à l'étage ventriculaire, 1 patient, $1 \%$ ). The REV was accomplished by exposing the morphologic left coronary artery in the $\mathrm{AV}$ groove to facilitate direct connection of the mobilized and divided main pulmonary artery on the shoulder of the heart so as to minimize anterior compression of the right ventricular outflow tract by the sternum.

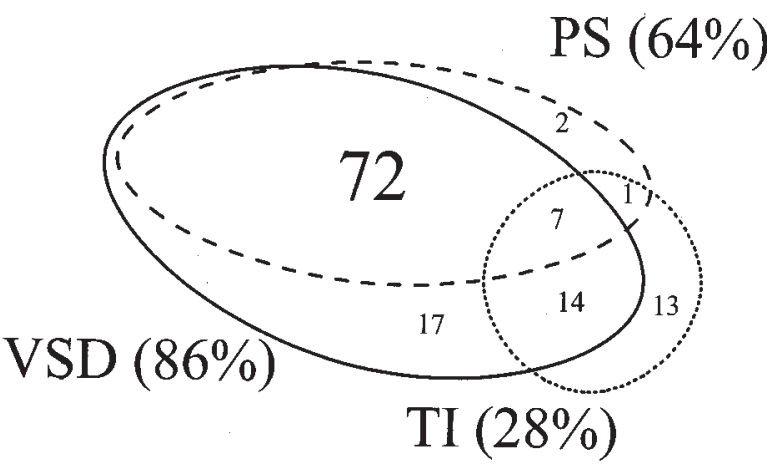

Fig 1. Associated lesions in AV discordance $(\mathrm{n}=127)$. Venn diagram depicting the overlap between the 3 most common associated lesions of AV discordance: VSD, PS, and TI. The total percentage of each associated lesion is indicated in parentheses. The numbers of patients with every possible combination of lesions is indicated by the numbers within the intersecting lines.

In the double switch (ie, Ilbawi) procedure to correct VA discordance, ${ }^{2}$ the left ventricular outflow was redirected to the aorta and the right ventricle was connected to the pulmonary artery either by an arterial switch $(n=1)$ or by a Rastelli procedure $(n=8)$. To correct AV discordance, an atrial switch (Mustard procedure) was added. One additional patient had AV discordance (with VSD) and was managed with a VSD repair and Mustard procedure to correct her isolated ventricular inversion.

Age at repair. Age at open biventricular repair ranged from newborn to 65 years (Fig 2A). The median age in the entire cohort at initial repair was 8 years, but age at repair varied by diagnosis (Fig 2B). For instance, patients undergoing biventricular repair for AV discordance who had isolated VSDs tended to undergo repair earliest at a median age of 3.5 years (range 0.1-12.8 years), whereas those with tricuspid valve regurgitation underwent valve repair or replacement at a median age of 16.6 years (range 0.6-65 years).

Statistical analysis. All Kaplan-Meier analyses were performed with SAS software (SAS Institute, Inc, Cary, NC). Comparisons between groups were made using the log-rank test. Survival was examined by Kaplan-Meier analysis either from date of initial repair or from date of birth. Although selecting only surgical patients introduced a selection bias, we believe such an analysis provides important insight into the history of patients with AV discordance and associated lesions requiring surgery. In particular, the age range for first operation is so wide within the cohort that it is illustrative to examine patient survival from birth, to demonstrate the survival of the surgical cohort as a whole.

With regard to reoperation (including tricuspid valve surgery, pacemaker placement, and conduit replacement), in addition to analyzing freedom from each of these events individually, also included is an analysis of freedom from the event or freedom from death. Since death precluded patients 

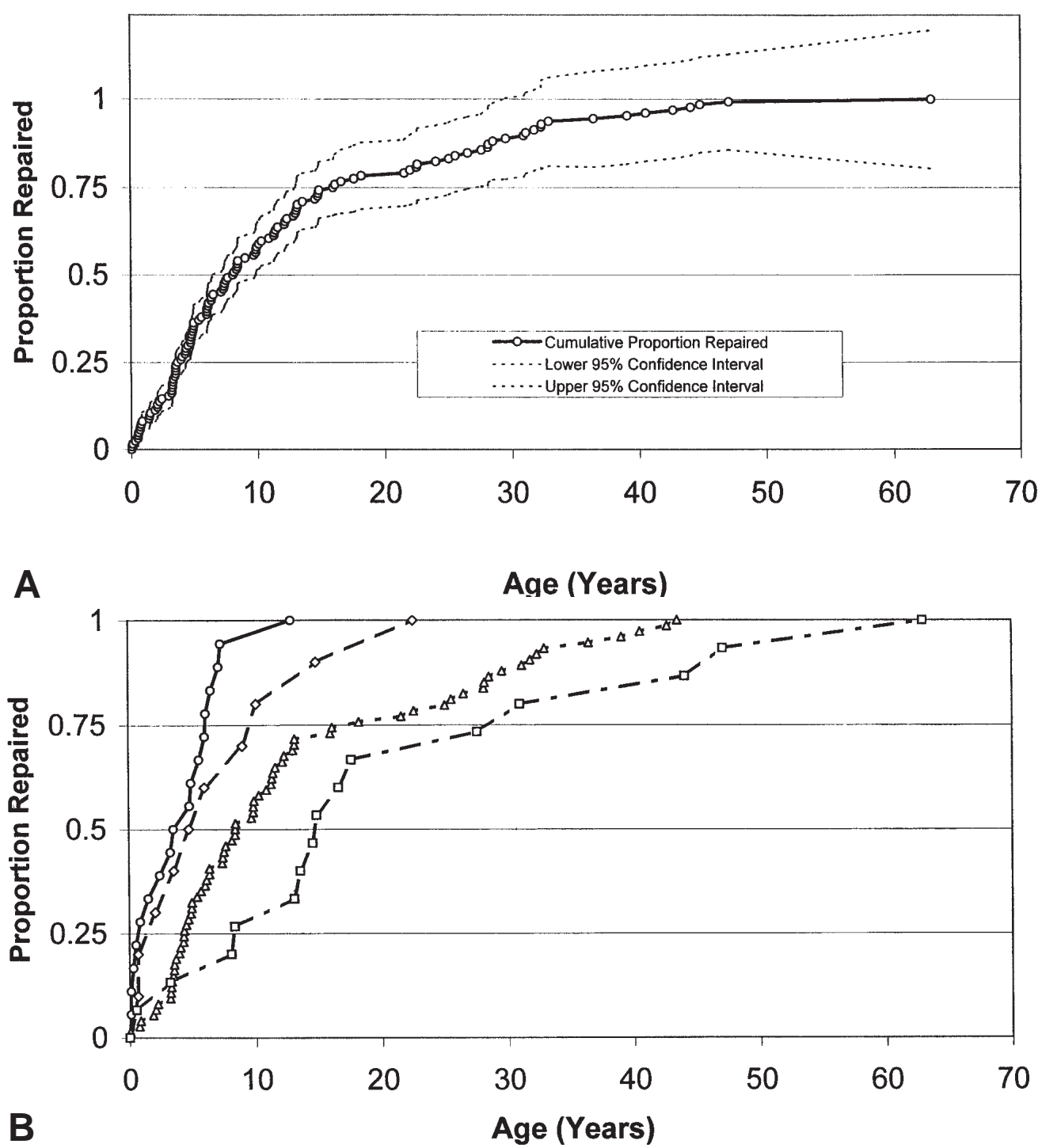

\section{$\multimap$ VSD Only - - VSD-PS $\rightarrow-$ VSD-TVR $\rightarrow-$ TVR Only}

Fig 2. A, Cumulative frequency of ages at which patients underwent biventricular repair for lesions associated with AV discordance. Entire cohort. B, Cumulative frequency of ages at which patients underwent biventricular repair for lesions associated with AV discordance. Subset analysis of major diagnostic groups. Patients with isolated VSDs underwent repair earliest at a mean age of 3.5 years. Those with tricuspid valve regurgitation (TVR) required surgery at a median age of 16.6 years.

from reoperation, omitting death as part of the censoring process for the event "reoperation" made freedom from reoperation appear better than it actually was.

\section{Results}

Survival of cohort. Survival of the cohort of patients with AV discordance (who underwent biventricular repair) is shown from date of operation (Fig 3A) and from date of birth
(Fig 3B). Seven of 127 patients died early after open repair (Table I), yielding an operative mortality of $6 \%$. Kaplan-Meier survival 20 years after the date of initial repair was $48 \%$ (Fig $3 \mathrm{~A})$. From date of birth, survival declined progressively over time and was 50\% at age 41 years (Fig 3B). To control for technologic advances in cardiac surgery, survival was compared between the first and second halves of the cohort, but it did not significantly vary between eras $(P=.24)$. 


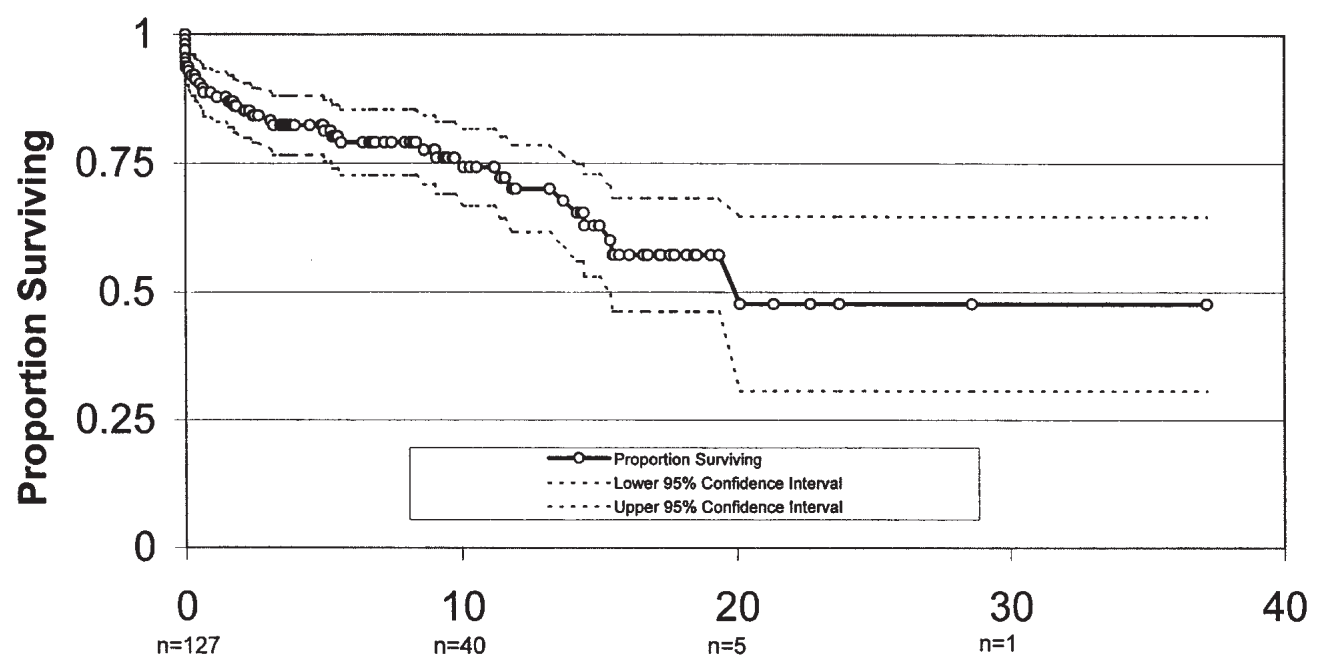

\section{A Years After Initial Repair}

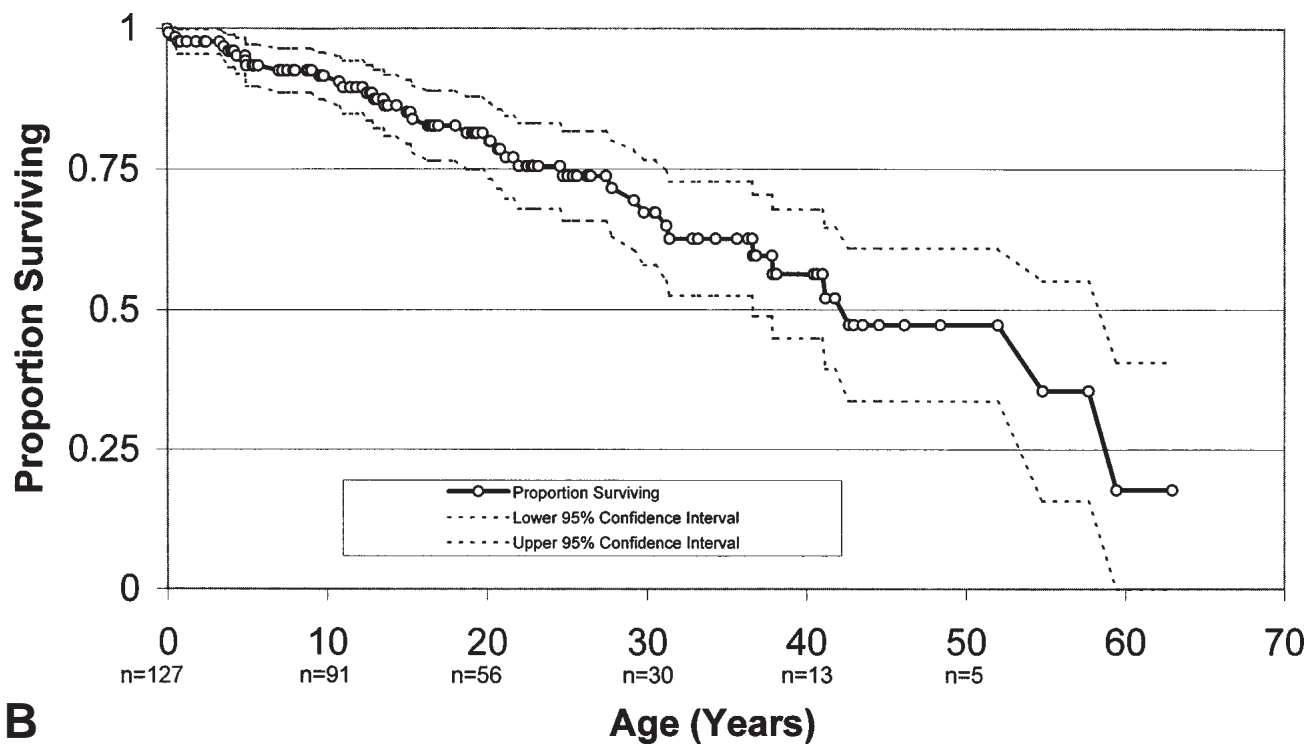

Fig 3. A, Kaplan-Meier survival of patients with AV discordance. Survival of the entire cohort $(n=127)$ from date of initial repair. B, Kaplan-Meier survival of patients with AV discordance. Survival of the entire cohort from date of birth.

Subset analysis of our early experience with the double switch procedure revealed an early mortality (1/9 patients) that was similar to that of conventionally managed patients; however, maximum follow-up was only 8.6 years.

Survival by type of repair. Survival revealed no significant differences among the 4 major diagnostic groups in the cohort when analyzed from date of initial repair (Fig $3 C, P=.36$ ). Although survival in patients with isolated VSDs appeared to be better, this trend was not statistically significant $(P=.86)$. Whether or not the discordance was corrected by means of the double switch procedure also did not affect survival; however, maximum follow-up of the 9 patients undergoing a double switch procedure is limited to 8.6 years, at which time patient survival is $89 \%$.

Reoperation. The causes of late death are enumerated in Table II. Death at reoperation (usually from 


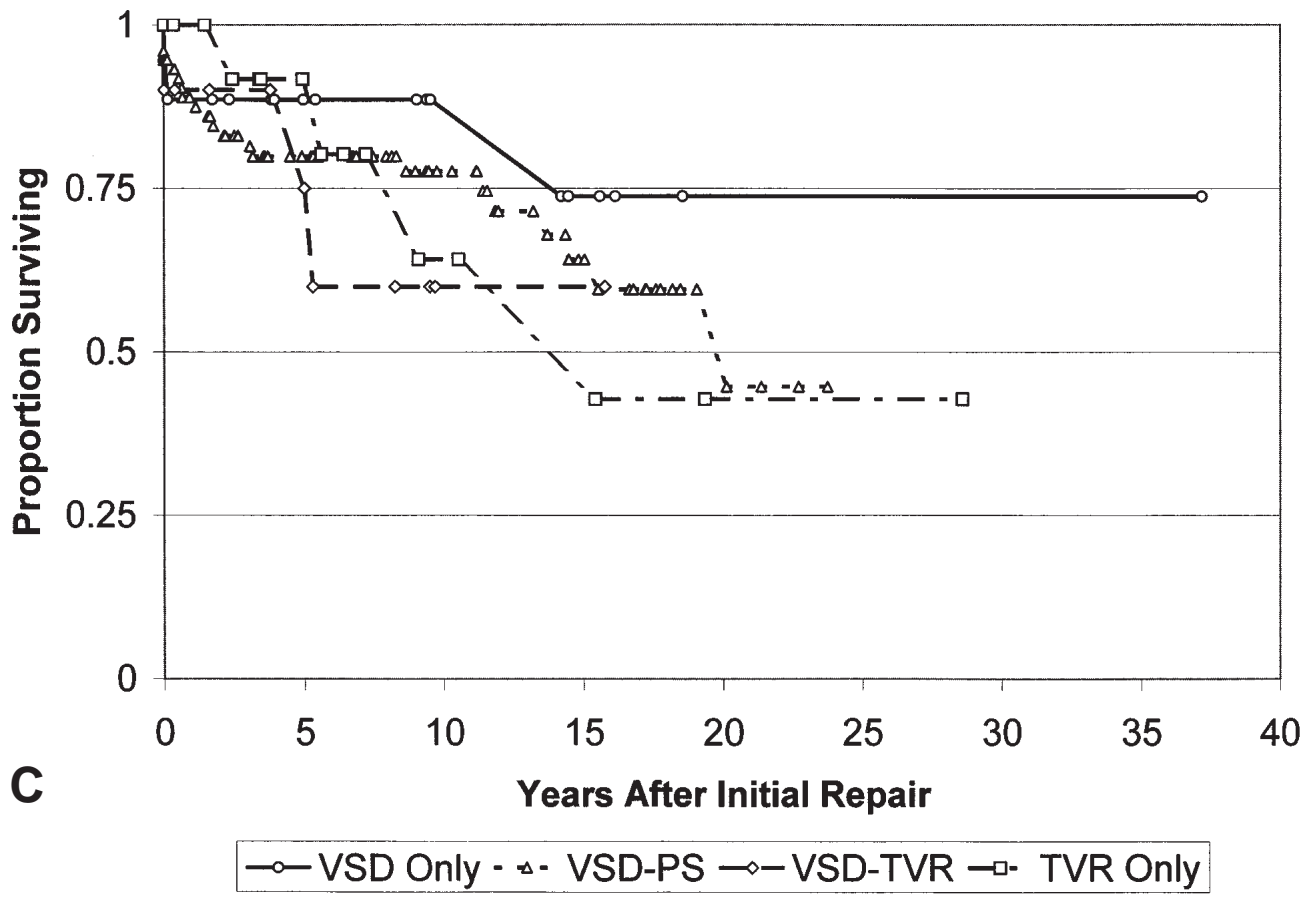

Fig 3C. Kaplan-Meier survival of patients with AV discordance. Survival of cohort from date of initial repair analyzed by major diagnostic group, that is, VSD only $(n=17)$, VSD-PS $(n=72)$, VSD-TVR $(n=14)$, and TVR only $(\mathrm{n}=13)$. $T V R$, Tricuspid valve regurgitation.

Table I. Operative mortality for initial repair and subsequent reoperations

\begin{tabular}{lcc}
\hline & $\begin{array}{c}\text { No. of deaths/ } \\
\text { No. of operations }\end{array}$ & $\begin{array}{c}\text { Operative } \\
\text { mortality (\%) }\end{array}$ \\
\hline First repair & $7 / 127$ & 6 \\
First reoperation & $7 / 41$ & 17 \\
Second reoperation & $2 / 3$ & 67 \\
Third reoperation & $0 / 1$ & 0 \\
Fourth reoperation & $0 / 1$ & 0 \\
Fifth reoperation & $1 / 1$ & 100 \\
\hline
\end{tabular}

myocardial failure) accounted for $36 \%$ of late deaths. Sudden unexplained death, documented arrhythmia, and progressive myocardial failure comprised the remainder. Forty-four patients required 1 or more reoperations. The risk of death at reoperation increased exponentially with each procedure (Table I).

Freedom from reoperation (Fig 4A) revealed that, by 10 years, $65 \%$ of patients were free of reoperation; however, $15 \%$ of those patients had died before any reoperation. Notably, $80 \%$ of reoperations included procedures either for tricuspid regurgitation or for pulmonary conduit stenosis (Table III). Three patients required reoperation for residual VSD, 1 for endocardi-
Table II. Causes of late death after initial operation

\begin{tabular}{lcc}
\hline & No. & Late deaths $(\%)$ \\
\hline Reoperation & 10 & 36 \\
Sudden, unexplained & 8 & 29 \\
Documented arrhythmia & 3 & 11 \\
Progressive myocardial failure & 6 & 21 \\
Infection & 1 & 3 \\
\hline
\end{tabular}

tis, and 2 for myocardial failure (managed by heart transplantation). The original diagnosis for which the operation was performed had no effect on the rate of reoperation (Fig 4B).

In follow-up of our early experience with the double switch procedure $(n=9), 3$ of 8 survivors required reoperation for left ventricular outflow tract obstruction. One patient with bilateral superior venae cavae (SVCs) underwent a double switch procedure with bilateral cavopulmonary shunts (one and a half ventricle repair) but subsequently required left SVC ligation for pulmonary hypertension and resultant SVC syndrome. After the double switch procedure, subsequent valve surgery has not been required, but maximum follow-up is only 8.6 years.

Tricuspid valve failure. Tricuspid valve failure was 


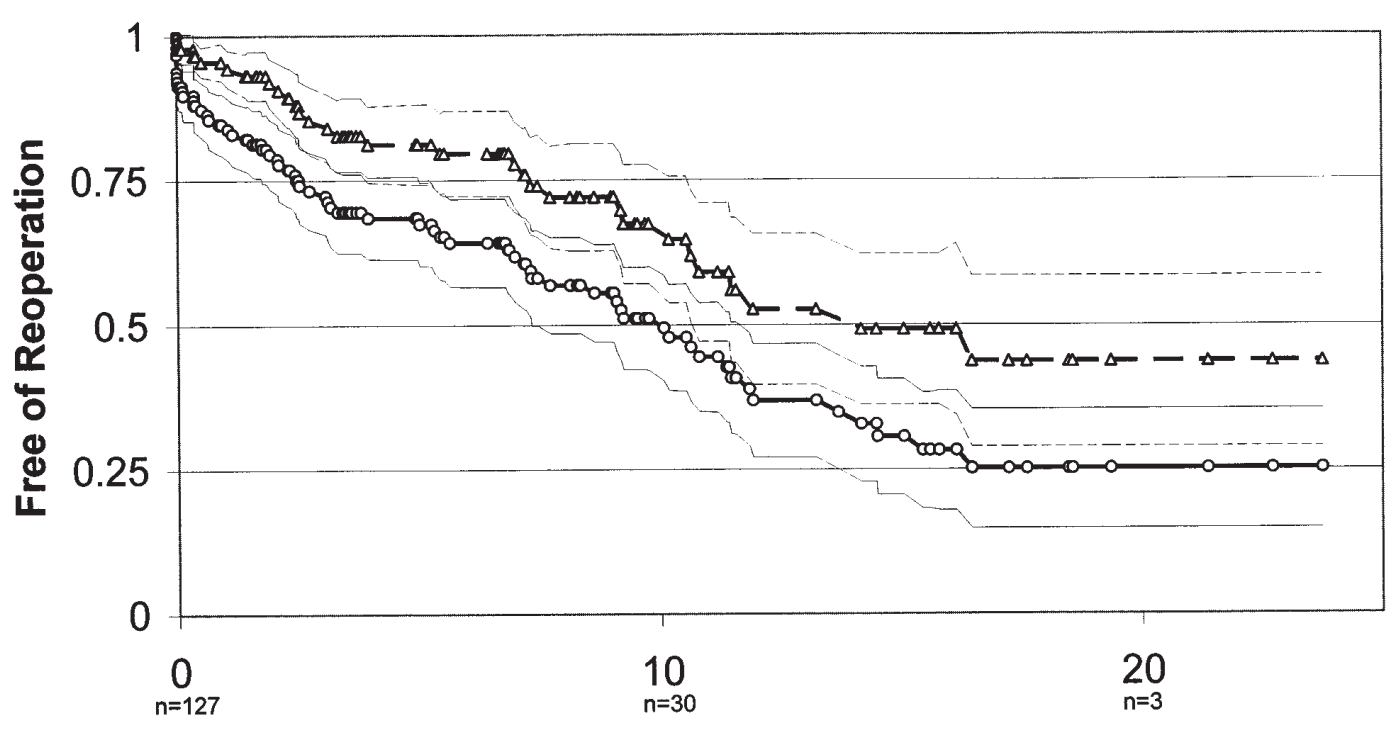

A

\section{Years After Initial Repair}

$=-$ Free of Reoperation or Death

$\triangle-$ Free of Reoperation

Lower $95 \%$ Confidence Interval for Reoperation or Death

Upper 95\% Confidence Interval for Reoperation or Death

- . - - - Lower 95\% Confidence Interval for Reoperation

_._-_- Upper 95\% Confidence Interval for Reoperation

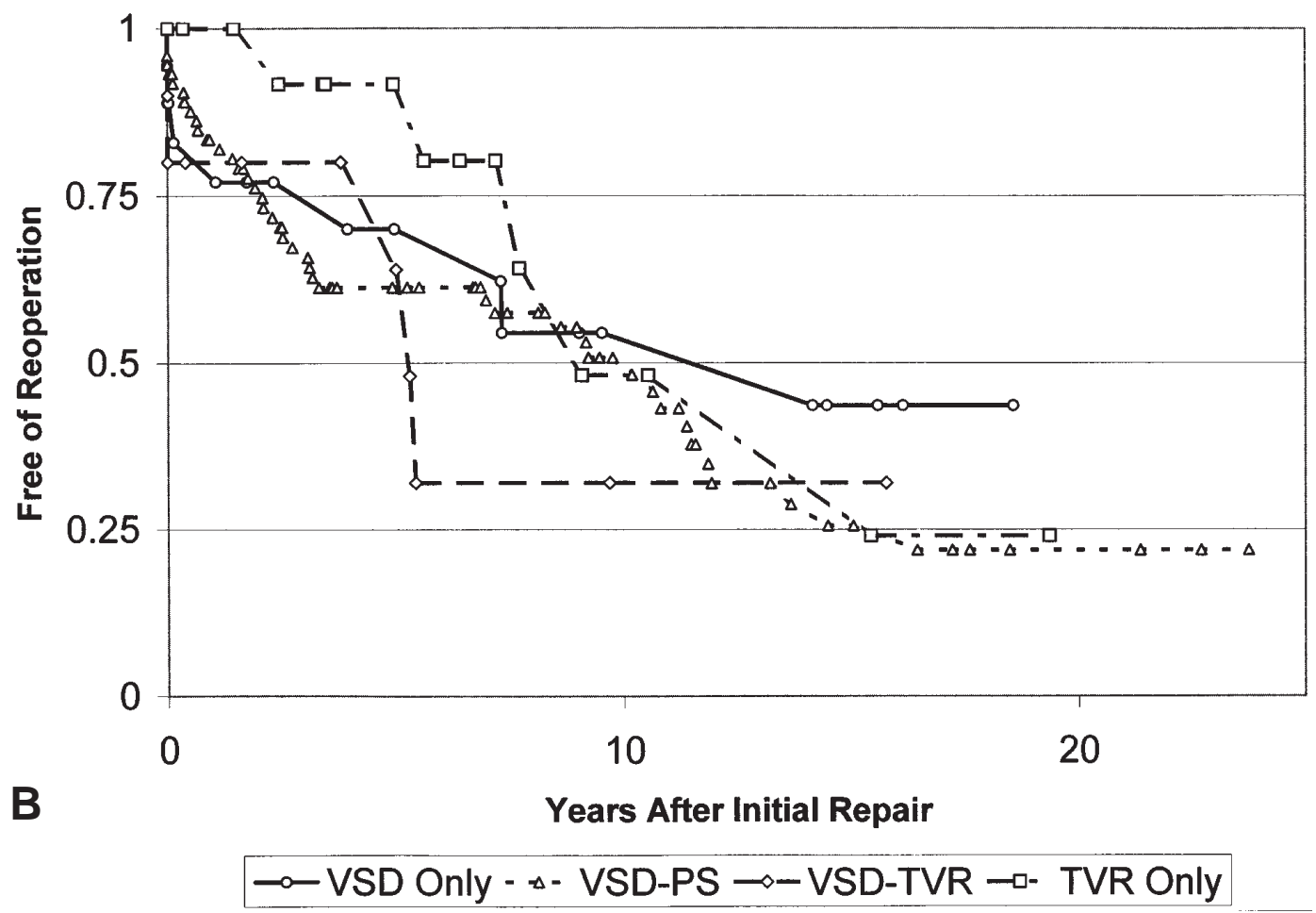

Fig 4. A, Freedom from reoperation in AV discordance. Entire cohort. B, Freedom from reoperation in AV discordance. Separation by original diagnosis. Since death precluded reoperation, freedom from reoperation and freedom from death are depicted; otherwise, freedom from reoperation alone was misleadingly high. 

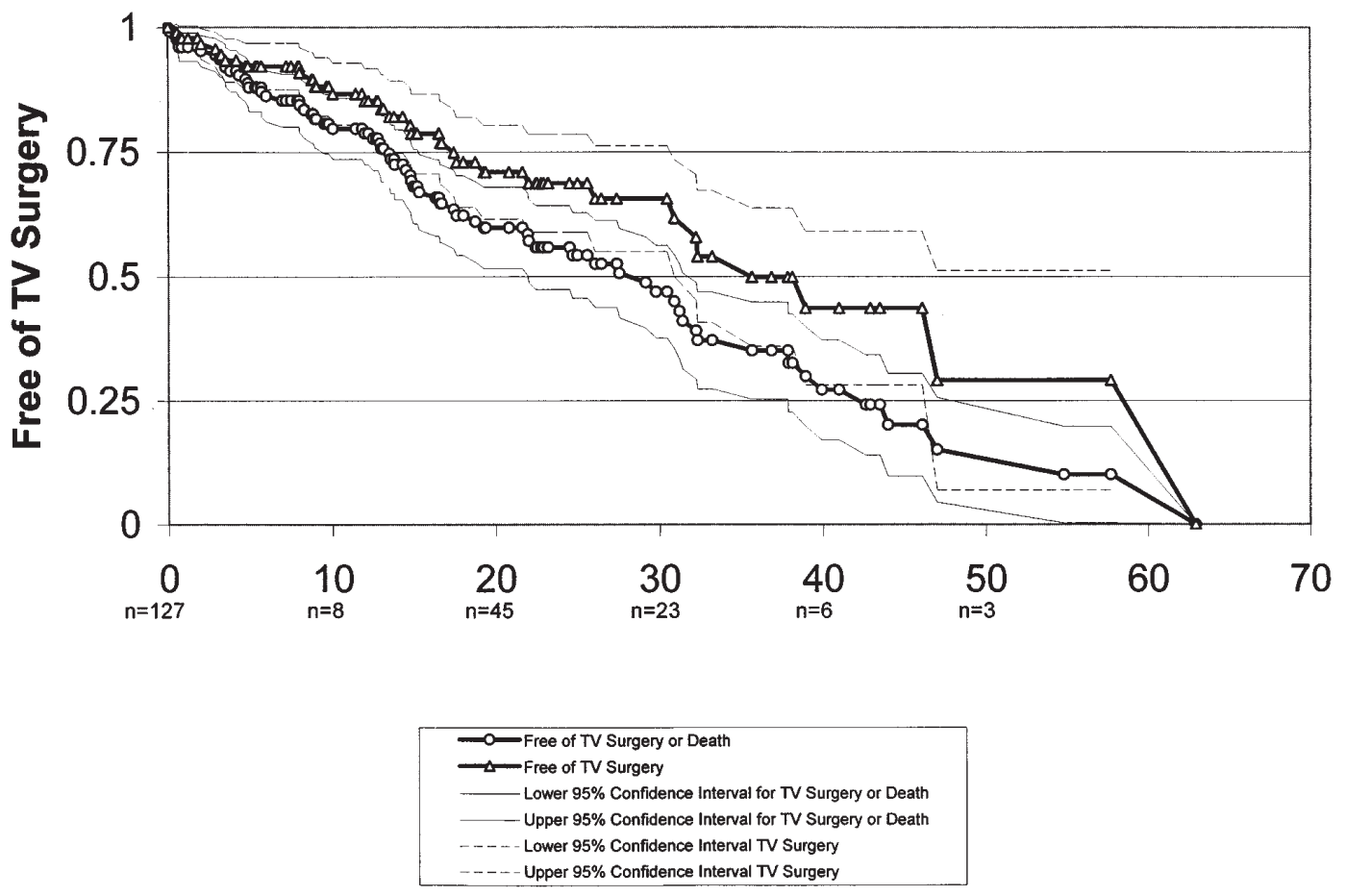

Fig 5. Freedom from tricuspid valve $(T V)$ surgery in AV discordance.

Table III. Indications for reoperation

\begin{tabular}{|c|c|c|c|}
\hline Reoperation & Reoperation type & No. & $\%$ \\
\hline \multirow[t]{11}{*}{ First $(n=41)$} & TVR & 16 & 36 \\
\hline & PS & 16 & 36 \\
\hline & Conduit failure & 14 & \\
\hline & No previous conduit & 2 & \\
\hline & TVR-PS & 3 & 7 \\
\hline & Residual VSD & 3 & 7 \\
\hline & $\begin{array}{l}\text { Heart transplant } \\
\text { ( } 1 \text { after double switch) }\end{array}$ & 2 & 3 \\
\hline & Infection & 1 & 2 \\
\hline & $\begin{array}{l}\text { LVOTO } \\
\text { (after double switch) }\end{array}$ & 3 & 7 \\
\hline & LSVC ligation & 1 & 2 \\
\hline & Total & 45 & 100 \\
\hline \multirow[t]{4}{*}{ Second $(\mathrm{n}=3)$} & VSD-conduit & 1 & 33 \\
\hline & TVR-MV repair & 1 & 33 \\
\hline & TVR & 1 & 33 \\
\hline & Total & 3 & 100 \\
\hline \multirow{2}{*}{$\begin{array}{l}\text { Third, fourth, and fifth } \\
(\mathrm{n}=1)\end{array}$} & TVR & 1 & 100 \\
\hline & Total & 1 & 100 \\
\hline
\end{tabular}

$T V R$, Tricuspid valve repair/replacement; $P S$, pulmonary stenosis; $V S D$, ventricular septal defect; $L V O T O$, left ventricular outflow tract obstruction; $L S V C$, left superior vena cava; $M V$, mitral valve.

an important cause of morbidity and mortality, both at initial repair and during subsequent follow-up. Fortytwo of 127 patients (34\%) have required tricuspid valve
Table IV. Cardiac arrhythmias: Summary of immediate preoperative and postoperative rhythms and need for perioperative pacemaker placement

\begin{tabular}{|c|c|c|c|c|}
\hline \multirow[b]{2}{*}{ Ryhthm } & \multicolumn{2}{|c|}{$\begin{array}{c}\text { Immediate } \\
\text { preop }\end{array}$} & \multicolumn{2}{|c|}{$\begin{array}{c}\text { Immediate } \\
\text { postop }\end{array}$} \\
\hline & No. & $\%$ & No. & $\%$ \\
\hline Sinus rhythm & 100 & 80 & 61 & 49 \\
\hline Complete AV block & 16 & 12 & 48 & 38 \\
\hline $\begin{array}{l}\text { Wolff-Parkinson-White } \\
\text { syndrome }\end{array}$ & 3 & 2 & 1 & 1 \\
\hline Sick sinus syndrome & 0 & 2 & 2 & 2 \\
\hline Supraventricular tachycardia & 3 & 2 & 4 & 3 \\
\hline Atrial fibrillation & 1 & 1 & 1 & 1 \\
\hline Other & 0 & 0 & 1 & 1 \\
\hline Pacemaker & 4 & 3 & 40 & 27 \\
\hline
\end{tabular}

repair or replacement to date. Twenty-seven of these required tricuspid valve replacement or repair at initial repair. Of these 27, 4 have required a subsequent operation for tricuspid valve failure at a mean age of 10 years (median 14.2 years) after the initial repair.

Of the 98 patients who did not require tricuspid valve surgery at initial repair, 14 (14\%) have required subsequent tricuspid valve surgery by a mean age of 19.9 years (median 17.4 years). Although some of these patients had Ebsteinoid anomaly of the tricuspid valve, 


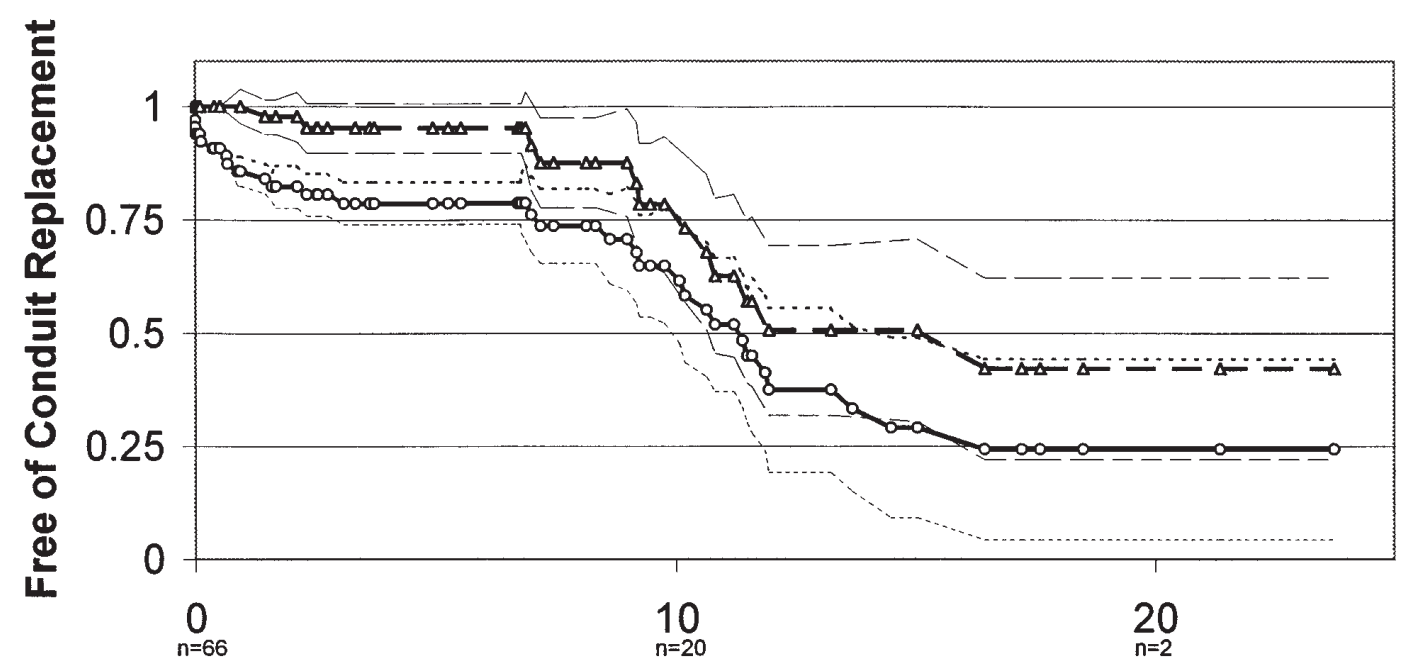

\section{Years After Initial Repair}

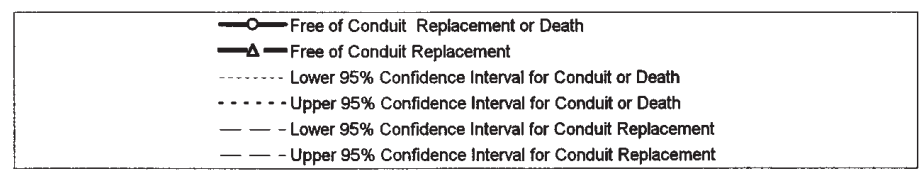

Fig 6. Freedom from pulmonary conduit replacement in AV discordance.

Table V. Advantages and disadvantages of conventional and novel management of both isolated VA discordance and $A V$ - $V A$ discordance

\begin{tabular}{lll}
\hline & \multicolumn{1}{c}{ Disadvantages } & \multicolumn{1}{c}{ Advantages } \\
\hline $\begin{array}{l}\text { VA discordance (simple transposition) } \\
\text { Atrial switch }\end{array}$ & Baffle complications & \\
& Obstruction & Proven long-term track record (in simple \\
& Leak & TGA) \\
& Atrial arrhythmias & \\
& Decreased activity level (?quality of life) & \\
& Morphologic RV failure in systemic position & \\
Arterial switch & Morphologic TV failure in systemic position & Anatomic correction (in theory) \\
& Propensity for late coronary artery obstruction & Morphologic LV in systemic position \\
& RVOTO from pulmonary artery reconstruction & Morphologic MV in systemic position \\
& & Better outcomes (in complex TGA) \\
& & Anatomic correction (in theory) \\
Rastelli procedure & LVOTO (baffle obstruction) & Morphologic LV in systemic position \\
& RVOTO from pulmonary artery reconstruction & Morphologic MV in systemic position \\
AV-VA discordance (corrected transposition) & Conduction system at risk with VSD enlargement & Better outcomes (in complex TGA) \\
Associated lesion repair & Ventricular dysfunction with VSD enlargement & \\
& Morphologic RV failure in systemic position & Simpler operation \\
Double switch & Morphologic TV failure in systemic position & \\
& Operative risk with uncertain benefits & Anatomic correction (in theory) \\
& Combined potential complications of: & Morphologic LV in systemic position \\
& Atrial switch (above) & Morphologic MV in systemic position \\
& Arterial switch or Rastelli (above) & \\
\hline
\end{tabular}

$V A$, Ventriculoarterial; $A V$, atrioventricular; $R V$, right ventricular; $T V$, tricuspid valve; $R V O T O$, right ventricular outflow tract obstruction; $L V O T O$, left ventricular outflow tract obstruction; $V S D$, ventricular septal defect; $T G A$, transposition of the great arteries; $L V$, left ventricular; $M V$, mitral valve. 


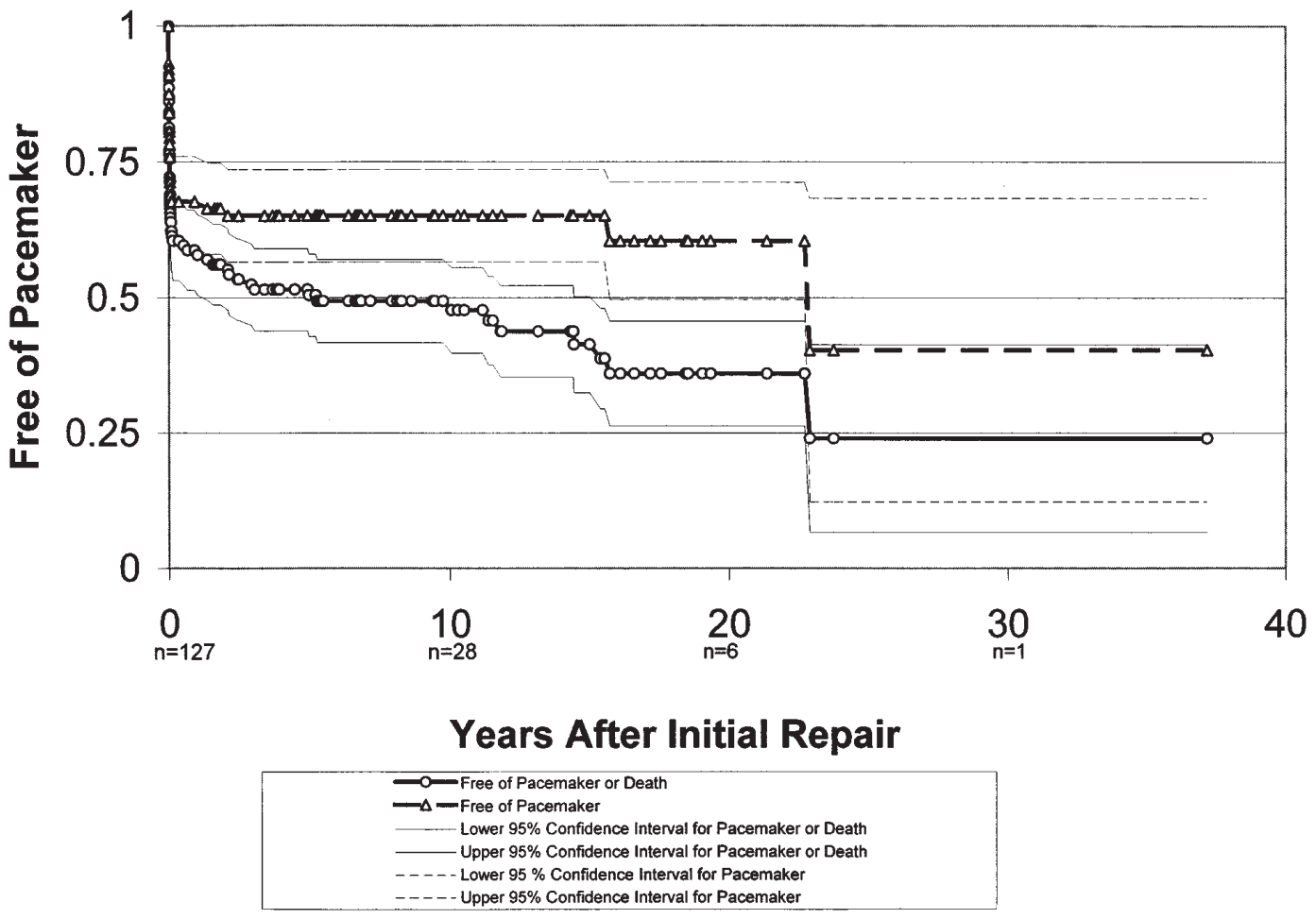

Fig 7. Freedom from pacemaker placement in AV discordance.

the exact tricuspid valve disease is unknown in our cohort for several reasons. The defect in the tricuspid valve was often subtle; some patients underwent surgery before the advent of echocardiography, and the left-sided AV valve was difficult to visualize at surgery.

Fifty percent of patients with AV discordance required tricuspid valve surgery by age 35 years (Fig 5). Tricuspid valve failure requiring surgery increased with age. When we compared patients who underwent tricuspid valve surgery at initial repair versus those who required tricuspid valve surgery after their initial repair, no difference in actuarial survival was noted.

Pulmonary conduit failure. Pulmonary conduit failure was an important source of morbidity and mortality (Fig 6). Of the 66 patients who had pulmonary conduits placed at initial repair, within 12 years $49 \%$ required conduit replacement; however, an additional $13 \%$ had died before coming to conduit replacement.

AV block. Preoperatively, $80 \%$ of patients were in sinus rhythm, $12 \%$ in complete AV block (including $3 \%$ who required pacemakers, as shown in Table IV). Postoperatively, $49 \%$ of patients were in normal sinus rhythm, $38 \%$ in complete AV block, and $27 \%$ were supported by a pacemaker. The majority of AV blocks occurred early, but with minimal ongoing attrition of the conduction system with age (Fig 7). Twenty years after the initial repair, $60 \%$ of patients were free of pacemaker placement. The presence of situs inversus did not increase the need for perioperative pacemaker placement. Because of the recognized propensity for $\mathrm{AV}$ block to develop in patients with $\mathrm{AV}$ discordance, ${ }^{3}$ one might expect that pacemaker placement would confer a survival advantage; however, patients who required pacemakers had no better (or worse) survival than those who did not. In our early experience with the double switch procedure, 5 of 9 required perioperative pacemaker placement for complete AV block.

\section{Discussion}

Historically, the management of AV-VA discordance has been directed at the frequent presence of associated lesions (VSD, PS, and TI), as well as the development of progressive AV block over time. In this series, the majority of patients were managed conventionally by repairing associated lesions and not addressing discordant connections. Substantial late morbidity and mortality with this algorithm were a result of the recognized natural and postoperative history of AV discordance. Sudden death, documented arrhythmia, and progressive myocardial dysfunction account for the largest 
Table VI. Historical comparison of management algorithms for VA and AV-VA discordance comparing survival when VA discordance was not corrected versus survival when VA discordance was corrected

\begin{tabular}{|c|c|c|c|c|}
\hline \multirow{2}{*}{\multicolumn{2}{|c|}{ Discordance }} & \multirow[b]{3}{*}{ Time } & \multicolumn{2}{|l|}{ Survival } \\
\hline & & & If $\mathrm{V}$ d lis d & If VA dis do \\
\hline Type & Complexity & & uncorrected & corrected \\
\hline \multirow[t]{4}{*}{ AV } & Simple & 10 year & $89 \% *$ & $88 \% *$ \\
\hline & & 20 year & $77 \% *$ & $? ? ?$ \\
\hline & Complex (usually VSD) & 10 year & $63 \% *$ & $77 \% *$ \\
\hline & & 20 year & $46 \% *$ & $? ? ?$ \\
\hline \multirow[t]{4}{*}{ AV-VA } & Simple & 10 year & Too rare & Too rare \\
\hline & & 20 year & Too rare & Too rare \\
\hline & Complex (usually VSD, PS, TI) & 10 year & $76 \%$ & $? ? ?$ \\
\hline & & 20 year & $48 \%$ & $? ? ?$ \\
\hline
\end{tabular}

The similar 20-year survival for complex VA discordance to that for "complex" AV-VA discordance managed without correcting VA discordance suggests that failing to restore VA concordance results in suboptimal survival. The advent of the arterial switch (ie, correction of VA discordance) improved 10-year survival in complex transposition by $14 \%$. Can we anticipate a similar improvement in AV-VA discordance with the double switch operation? $A V$, Atrioventricular; $V A$, ventriculoarterial; VSD, ventricular septal defect; $P S$, pulmonary stenosis; $T I$, tricuspid insufficiency; ???, data not available yet. *Unpublished data, University of Toronto.

proportion of late deaths. The Mayo Clinic reported the development of spontaneous AV block and found that the risk was $2 \%$ per year after diagnosis. ${ }^{3}$ Our outcomes are probably explained by the theories that have been advanced to explain the natural history of discordance, that is, (1) failure of the morphologic right ventricle in the systemic position, (2) failure of the morphologic tricuspid valve in the systemic position, and (3) failure of the conduction system. Indeed, these problems are interrelated and each has been postulated to result in the other two. Which was primarily responsible was impossible to discern retrospectively.

Controversies in the pathophysiology of $\mathrm{AV}$ discordance. In some patients, repair of VSD with or without left ventricular outflow tract obstruction may have led to progressive systemic AV valve regurgitation. ${ }^{4}$ Because function of the morphologic right ventricle was often depressed, discerning whether valve regurgitation reflects a failing right ventricle and annular dilatation or whether severe $\mathrm{AV}$ valve regurgitation has negatively affected ventricular function was problematic. In some older patients with AV and VA discordance "in isolation," right ventricular function is seemingly preserved. A number of reports of adults aged 60 to 80 years with AV discordance suggest that the morphologic right ventricle may function successfully as the systemic ventricle for a normal life span in patients with no major associated lesions. ${ }^{5-9}$ Radionuclide assessment of ventricular function supports this as well. ${ }^{10}$ In contrast, data from Peterson and associates ${ }^{11}$ suggested that patients with AV discordance have an abnormal exercise response in that they failed to increase their systemic ejection fraction with exercise. Regardless of the ongoing debate, multiple centers have reported disappointing 10-year survival using conventional management (Table VII). ${ }^{12-18}$ In our series, survival 20 years after the initial repair was only $48 \%$.

Lessons learned in the management of complete transposition (VA discordance). It is interesting to review the historical and current management algorithms for complete transposition (VA discordance) with respect to morbidity (Table $\mathrm{V}$ ) and mortality (Table VII). The atrial switch procedures (Mustard, Senning $)^{19}$ and procedures designed to correct VA discordance (Jatene arterial switch, Rastelli procedure $)^{20-22}$ each have their own shortcomings.

In analyzing outcomes (Table VI), surgical correction of discordant VA connections resulted in superior preservation of systemic (left) ventricular function and systemic (mitral) valve competence. Furthermore, avoidance of atrial switch procedures protected atrial conduction. Although survival was not improved in simple transposition of the great arteries (Table VI), in the treatment of complex transposition (typically associated with VSD), correcting VA connections improved 10 -year survival to $77 \%$ (versus $63 \%$ obtained using the Mustard procedure). ${ }^{23}$ Teleologically, this improvement supports the theory that correcting discordant VA connections relieves the morphologic right ventricle and the tricuspid valve of the need to support systemic hemodynamic loads and is more important in patients who have a major associated lesion than in those with isolated complete transposition.

Parallels in the pathophysiology of AV discor- 
Table VII. Comparison of existing AV discordance series: Management was either conventional or double switch operation. [NA: data not available].

\begin{tabular}{|c|c|c|c|c|c|c|c|}
\hline $\begin{array}{l}\text { Year } \\
\text { published }\end{array}$ & $\begin{array}{c}\text { First } \\
\text { author }\end{array}$ & Location & Country & $\begin{array}{c}\text { Years } \\
\text { of study }\end{array}$ & $\begin{array}{l}\text { Arterial } \\
\text { switches }\end{array}$ & $\begin{array}{c}\text { Biventricular } \\
\text { repairs } \\
\text { (No. patients) }\end{array}$ & $\begin{array}{c}\text { Deaths } \\
\text { (operative) }\end{array}$ \\
\hline \multicolumn{8}{|c|}{ Conventional management } \\
\hline 1981 & Huhta $^{12}$ & Rochester, MN & USA & $1951-81$ & NA & 55 & 15 \\
\hline 1982 & Hwang ${ }^{13}$ & New York, NY & USA & $1969-80$ & NA & 18 & 2 \\
\hline 1982 & Westerman $^{18}$ & Boston, MA & USA & $1974-81$ & NA & 23 & 2 \\
\hline 1985 & McGrath $^{14}$ & Birmingham, $\mathrm{AL}$ & USA & $1967-83$ & NA & 99 & 14 \\
\hline 1995 & Sano $^{15}$ & Melbourne & Australia & $1980-93$ & NA & 28 & 1 \\
\hline 1996 & Szufladowicz ${ }^{16}$ & London & England & $1975-90$ & NA & 87 & 13 \\
\hline 1996 & Termingnon $^{17}$ & Paris & France & 1974-94 & NA & 52 & 8 \\
\hline 1997 & Yeh & Toronto & Canada & $1959-97$ & NA & 118 & 6 \\
\hline Summary & & & & & & 480 & 61 \\
\hline \multicolumn{8}{|c|}{ Double switch } \\
\hline 1990 & Ilbawi $^{2}$ & Chicago, IL & USA & NA & 0 & 2 & 0 \\
\hline 1992 & Di Donato ${ }^{24}$ & Rome & Italy & NA & 0 & 2 & 0 \\
\hline 1994 & $\operatorname{Imai}^{25}$ & Tokyo & Japan & $1989-93$ & 3 & 18 & 2 \\
\hline 1994 & Yagihara $^{26}$ & Osaka & Japan & $1987-93$ & 4 & 10 & 1 \\
\hline 1995 & Stumper ${ }^{27}$ & Birmingham & England & $1991-93$ & 0 & 4 & 0 \\
\hline 1996 & Delius $^{28}$ & London & England & 1993-94 & 1 & 3 & 0 \\
\hline 1997 & Yeh & Toronto & Canada & $1988-97$ & 2 & 9 & 1 \\
\hline Summary & & & & & 10 & 48 & 4 \\
\hline
\end{tabular}

CHB, Complete heart block; $P M$, pacemaker.

dance. To some degree, isolated AV discordance is analogous to simple transposition of the great arteries (no major associated lesions). Both share the pathophysiologic combination of a morphologic right ventricle and tricuspid valve supporting the systemic circulation (although the tricuspid valve is more frequently abnormal in AV discordance). When AV discordance in isolation was examined, our experience was too small $(\mathrm{n}=1)$ for meaningful analysis. This patient (with $\mathrm{AV}$ discordance, VA concordance, and VSD) underwent a Mustard procedure and VSD repair at 17 months of age and continues to do well 11.4 years after repair. Like patients with VA discordance after arterial switch, one would expect such patients with isolated AV discordance to have a favorable natural history once concordance was surgically established between the morphologic left ventricle and systemic circulation.

Unfortunately, patients with AV discordance almost always have associated lesions; therefore, AV discordance is conceptually similar to complex transposition of the great arteries (transposition and VSD). The survival of patients with AV discordance managed conventionally is remarkably similar to that of complex VA discordance managed with an atrial switch operation (therefore without correcting VA connections, Table VI). ${ }^{23}$ Inferentially, the residual pathophysiologic problem in both VA discordance after atrial switch and AV-
VA discordance managed conventionally without correcting discordant connections is that the morphologic right ventricle and tricuspid valve are exposed to systemic hemodynamic loads.

The double switch procedure: Panacea or Pandora's box? In 1988, to address this concern, de Leval and associates ${ }^{1}$ first theorized the double switch procedure. Ilbawi and colleagues, ${ }^{2}$ in 1990 , were the first to report successful cases $(n=2)$. The results of all published series in which this approach was used $\mathrm{d}^{2,24-28}$ are summarized in Table VII and compared with other published series using conventional correction of associated lesions. ${ }^{12-18}$ Operative mortality was similar to that of conventional repair, but long-term follow-up was insufficient to conclude an overall superiority for this procedure. Our data for conventional repair (74\% survival at 10 years and $48 \%$ survival 20 years after repair) suggest that differences in survival may not become evident until 10 years of follow-up have elapsed.

Because AV discordance is uncommon, published series are relatively small. Small numbers of patients combine with institutional biases (including our own) to make objective demonstrations of superiority (by randomized controlled trial) extremely unlikely. The double switch operation combines 2 operations: an atrial switch procedure (Mustard or Senning) and a procedure to correct VA discordance (either a Jatene arterial 


\begin{tabular}{|c|c|c|c|c|c|c|}
\hline $\begin{array}{c}\text { Deaths } \\
\text { (late) }\end{array}$ & $\begin{array}{c}C H B \\
\text { requiring } \\
P M(\text { perioperative })\end{array}$ & $\begin{array}{c}\text { Mean } \\
\text { follow-up } \\
(y)\end{array}$ & $\begin{array}{c}\text { Actuarial } \\
\text { survival } \\
(10 y)\end{array}$ & $\begin{array}{c}\text { Actuarial } \\
\text { survival } \\
(20 y)\end{array}$ & $\begin{array}{c}\text { Mortality } \\
\text { (operative) }\end{array}$ & $\begin{array}{c}\text { Mortality } \\
\text { (cohort } \\
\text { to date) }\end{array}$ \\
\hline 29 & 12 & NA & $54 \%$ & NA & $27 \%$ & $80 \%$ \\
\hline 2 & 2 & 4.5 & NA & NA & $11 \%$ & $22 \%$ \\
\hline 3 & 6 & NA & NA & NA & $9 \%$ & $22 \%$ \\
\hline 18 & 23 & NA & $68 \%$ & NA & $14 \%$ & $32 \%$ \\
\hline 0 & 9 & 5.8 & $83 \%$ & NA & $4 \%$ & $4 \%$ \\
\hline 4 & 17 & NA & $68 \%$ & NA & $15 \%$ & $20 \%$ \\
\hline 8 & 14 & 7.6 & $71 \%$ & NA & $15 \%$ & $31 \%$ \\
\hline 28 & 33 & 8.0 & $75 \%$ & $48 \%$ & $5 \%$ & $29 \%$ \\
\hline 92 & 116 & NA & $70 \%$ & $48 \%$ & $13 \%$ & $32 \%$ \\
\hline 0 & 0 & 0.8 & NA & NA & $0 \%$ & $0 \%$ \\
\hline NA & 0 & 0.5 & NA & NA & $0 \%$ & $0 \%$ \\
\hline 0 & 0 & 1.9 & NA & NA & $11 \%$ & $11 \%$ \\
\hline 2 & 1 & 0.9 & NA & NA & $10 \%$ & $30 \%$ \\
\hline 0 & 1 & NA & NA & NA & $0 \%$ & $0 \%$ \\
\hline NA & 0 & 0.9 & NA & NA & $0 \%$ & $0 \%$ \\
\hline 0 & 5 & 2.3 & NA & NA & $11 \%$ & $11 \%$ \\
\hline 0 & 7 & NA & NA & NA & $5 \%$ & $7 \%$ \\
\hline
\end{tabular}

switch in the absence of pulmonary stenosis or a Rastelli-like procedure in the presence of VSD and PS). After a double switch procedure, Imai and coworkers ${ }^{25}$ reported a decrease in right ventricular end-diastolic volume from $122 \%$ to $78 \%$ with unloading of the right ventricle and no significant change in left ventricular end-diastolic volume before (134\% of normal) and after ( $127 \%$ of normal) the procedure. The early development of 3 cases of left ventricular outflow tract obstruction in our series after Mustard/Rastelli repair was disconcerting and argues for careful and ongoing follow-up of patients managed by this algorithm. The Rastelli procedure is most easily accomplished when the VSD is anterior, muscular, subaortic, and also free of conduction tissue. The more typical inlet perimembranous VSD presents more of a challenge. Furthermore, in our hands, the incidence of acquired complete AV block was high. Others have avoided AV block (Table VII), and we believe that sinus rhythm can be preserved by avoiding technical errors in tunnel construction. Paradoxically, the high incidence of block in corrected transposition may be protective against the supraventricular tachycardias incurred after atrial switch procedures. Finally, in cases in which a pulmonary conduit was used, and possibly even in cases in which an REV procedure was employed, ${ }^{29}$ the morbidity arising from conduit stenosis will be formidable.
Results with conventional management of AV discordance were disappointing. Elimination of pulmonary conduits by using an REV procedure, advancements in pulmonary conduit preservation and longevity, and elucidation of differences between surgical techniques (or patient substrate) allowing more successful avoidance of complete AV block may diminish risks of the double switch approach.

Anecdotally, the single atrial switch/arterial switch in our series had an excellent result. Patients amenable to an arterial switch as part of a double switch repair will not have PS and are unlikely to have a restrictive VSD. It is probable that an atrial switch/Rastelli combination (used for the diagnosis combination of VSD and PS) is associated with significantly higher morbidity and mortality than the atrial switch/arterial switch combination (typically used for the diagnosis of VSD or tricuspid regurgitation). The subgroup eligible for the atrial switch/arterial switch combination are ideal double switch candidates and will avoid the problems of the Rastelli procedure (intraventricular tunnel stenoses and pulmonary conduit failure), as well as the problems of AV/VA discordance (tricuspid valve incompetence and right ventricular dysfunction).

For completeness, 2 alternatives to conventional management or double switch procedures should also be considered. Many patients with AV discordance and 
PS remain free of symptoms for years. Some benefit from Helen Taussig's philosophy of placing a systemic-pulmonary artery shunt as long-term definitive palliation. This approach was not examined in our cohort; however, these data serve as the baseline for future comparisons. A second alternative would be converting these patients to a univentricular circulation, avoiding the morbidity and mortality associated with iatrogenic AV block and pulmonary conduit failure. Twenty-year survival after Fontan's procedure for patients with a single ventricle at our institution was $50 \%$ to $60 \%$, but a univentricular conversion in a patient with 2 adequate ventricles may not provide superior survival or quality of life.

The theoretic advantage of correcting discordant AV connections must outweigh the complications of the component procedures comprising a double switch. Inasmuch as early mortality using the double switch procedure was no higher than that obtained with conventional management of $\mathrm{AV}$ discordance (Table VII), and since 20-year survival of conventionally managed patients who did not undergo correction of VA discordance was only $48 \%$ (Table VI), continued application of the double switch procedure seems reasonable in the expectation that correcting VA discordance will provide a survival advantage as it did in complex transposition. The patients in whom an arterial switch can be used are ideal candidates for the double switch. Perhaps a randomized controlled trial would most rapidly identify any advantage (or danger) of using this approach.

\section{Conclusions}

Patients undergoing operative repair with discordance at the Hospital for Sick Children and the Toronto Congenital Cardiac Centre for Adults were analyzed. Results of conventional management were disappointing, with important morbidity and mortality from a recognized predisposition of AV discordance for tricuspid valve failure, right ventricular dysfunction, and conduction system failure. Additionally, important problems were encountered with postoperative AV conduction block and pulmonary conduit failure.

Twenty years after initial repair, only $48 \%$ of the cohort was surviving (average patient age 42 years). Within 16 years, $57 \%$ of patients required reoperation and $35 \%$ required pacemaker placement. Within 12 years of conduit placement, $50 \%$ of patients required conduit replacement. By age 40,47\% of patients had required tricuspid valve surgery. Early results with the double switch operation were encouraging, with equivalent early mortality to conventional management; however, its potential advantages will require longterm follow-up.

\section{REFERENCES}

1. de Leval MR, Bastos P, Stark J, Taylor JF, Macartney FJ, Anderson RH. Surgical technique to reduce the risks of heart block following closure of ventricular septal defect in atrioventricular discordance. J Thorac Cardiovasc Surg 1979;78:515-26.

2. Ilbawi MN, DeLeon SY, Backer CL, et al. An alternative approach to the surgical management of physiologically corrected transposition with ventricular septal defect and pulmonary stenosis or atresia. J Thorac Cardiovasc Surg 1990;100:410-5.

3. Huhta JC, Maloney JD, Ritter DG, Ilstrup DM, Feldt RH. Complete atrioventricular block in patients with atrioventricular discordance. Circulation 1983;67:1374-7.

4. Congenitally corrected transposition of the great arteries (atrioventricular and ventriculoarterial discordance). In: Freedom RM, Mawson JB, Yoo SJ, Benson LN, editors. Congenital heart disease: textbook of angiocardiography. First edition. Armonk [NY]: Futura; 1997. p. 1071-117.

5. Lundstrom U, Bull C, Wyse RK, Somerville J. The natural and "unnatural" history of congenitally corrected transposition. Am J Cardiol 1990;65:1222-9.

6. Ferencz C, Rubin JD, McCarter RJ, et al. Congenital heart disease: prevalence at livebirth. The Baltimore-Washington Infant Study. Am J Epidemiol 1985;121:31-6.

7. Benchimol A, Sundararajan V. Congenital corrected transposition of the great vessels in a 58-year-old man. Chest 1971;59:634-8.

8. Lieberson AD, Schumacher RR, Childress RH, Genovese PD. Corrected transposition of the great vessels in a 73-year-old man. Circulation 1969;39:96-100.

9. Warnes CA. Congenitally corrected transposition: the uncorrected misnomer [editorial; comment]. J Am Coll Cardiol 1996;27:1244-5.

10. Benson LN, Burns R, Schwaiger M, et al. Radionuclide angiographic evaluation of ventricular function in isolated congenitally corrected transposition of the great arteries. Am J Cardiol 1986;58:319-24.

11. Peterson RJ, Franch RH, Fajman WA, Jones RH. Comparison of cardiac function in surgically corrected and congenitally corrected transposition of the great arteries. J Thorac Cardiovasc Surg 1988;96:227-36.

12. Huhta JC, Danielson GK, Ritter DG, Ilstrup DM. Survival in atrioventricular discordance. Pediatr Cardiol 1985;6:57-60.

13. Hwang B, Bowman F, Malm J, Krongrad E. Surgical repair of congenitally corrected transposition of the great arteries: results and follow-up. Am J Cardiol 1982;50:781-5.

14. McGrath LB, Kirklin JW, Blackstone EH, Pacifico AD, Kirklin JK, Bargeron LMJ. Death and other events after cardiac repair in discordant atrioventricular connection. J Thorac Cardiovasc Surg 1985;90:711-28.

15. Sano T, Riesenfeld T, Karl TR, Wilkinson JL. Intermediate-term outcome after intracardiac repair of associated cardiac defects in patients with atrioventricular and ventriculoarterial discordance. Circulation 1995;92(Suppl):II272-8.

16. Szufladowicz M, Horvath P, de Leval M, Elliott M, Wyse R, Stark J. Intracardiac repair of lesions associated with atrioventricular discordance. Eur J Cardiothorac Surg 1996;10:443-8.

17. Termignon JL, Leca F, Vouhe PR, et al. "Classic" repair of congenitally corrected transposition and ventricular septal defect. Ann Thorac Surg 1996;62:199-206.

18. Westerman GR, Lang P, Castaneda AR, Norwood WI. Corrected transposition and repair of associated intracardiac defects. Circulation 1982;66(Suppl):I197-202. 
19. Gelatt M, Hamilton RM, McCrindle BW, et al. Arrhythmia and mortality after the Mustard procedure: a 30-year single-center experience. J Am Coll Cardiol 1997;29:194-201.

20. Rubay J, Lecompte Y, Batisse A, et al. Anatomic repair of anomalies of ventriculo-arterial connection (REV): results of a new technique in cases associated with pulmonary outflow tract obstruction. Eur J Cardiothorac Surg 1988;2:305-11.

21. Williams WG, Quaegebeur JM, Kirklin JK, Blackstone EH. Outflow obstruction after the arterial switch operation: a multiinstitutional study. J Thorac Cardiovasc Surg 1997;114:975-90.

22. Bonhoeffer P, Bonnet D, Piechaud JF, et al. Coronary artery obstruction after the arterial switch operation for transposition of the great arteries in newborns. J Am Coll Cardiol 1997;29:202-6.

23. Williams WG. Coming of age with transposition. John Keith Lecture, Canadian Cardiovascular Society, Winnipeg, Manitoba. 1997.

24. Di Donato RM, Troconis CJ, Marino B, et al. Combined mustard and Rastelli operations: an alternative approach for repair of associated anomalies in congenitally corrected transposition in situs inversus \{I,D,D\}. J Thorac Cardiovasc Surg 1992;104:1246-8.
25. Imai Y, Sawatari K, Hoshino S, Ishihara K, Nakazawa M, Momma K. Ventricular function after anatomic repair in patients with atrioventricular discordance. J Thorac Cardiovasc Surg 1994;107:1272-83.

26. Yagihara T, Kishimoto H, Isobe F, et al. Double switch operation in cardiac anomalies with atrioventricular and ventriculoarterial discordance. J Thorac Cardiovasc Surg 1994;107:351-8.

27. Stumper O, Wright JG, De Giovanni JV, Silove ED, Sethia B, Brawn WJ. Combined atrial and arterial switch procedure for congenital corrected transposition with ventricular septal defect. Br Heart J 1995;73:479-82.

28. Delius RE, Stark J. Combined Rastelli and atrial switch procedure: anatomic and physiologic correction of discordant atrioventricular connection associated with ventricular septal defect and left ventricular outflow tract obstruction. Eur J Cardiothorac Surg 1996;10:551-5.

29. Lecompte Y, Neveux JY, Leca F, et al. Reconstruction of the pulmonary outflow tract without prosthetic conduit. J Thorac Cardiovasc Surg 1982;84:727-33. 